\title{
CALIBRATING CHLOROPHYLL METER (SPAD-502) READING BY SPECIFIC LEAF AREA FOR ESTIMATING LEAF NITROGEN CONCENTRATION IN SWEET SORGHUM
}

\author{
H. Uchino, ${ }^{1}$ T. Watanabe, ${ }^{1,2}$ K. Ramu, ${ }^{1}$ K. L. Sahrawat, ${ }^{1}$ S. Marimuthu, ${ }^{3}$ \\ S. P. Wani, ${ }^{1}$ and $\mathbf{O}$. Ito ${ }^{4}$ \\ ${ }^{1}$ International Crops Research Institute for the Semi-Arid Tropics (ICRISAT), \\ Patancheru, India \\ ${ }^{2}$ Japan International Research Center for Agricultural Sciences, Tsukuba, Japan \\ ${ }^{3}$ Agricultural Research Station, Tamil Nadu Agricultural University, Bhavanisagar, India \\ ${ }^{4}$ Institute for Sustainability and Peaces, United Nations University, Tokyo, Japan
}

\begin{abstract}
$\square \quad$ The chlorophyll meter (SPAD-502) is used to estimate nitrogen status of various crops. However, the relationship between $S P A D$ readings and leaf nitrogen concentration $(L N C)$ in sweet sorghum (Sorghum bicolor) has not been fully established. We examined the relationship between SPAD readings and $L N C$ in sweet sorghum in a two-year study; and the effects of leaf thickness on the relationship was also examined. There was a significant relationship between the SPAD reading and LNC at each of two growth stages, but the correlation was weaker when the data for the two growth stages were pooled. This correlation improved when the specific leaf area was introduced as a second independent variable in the multiple regression analysis. This regression equation was applicable to not only different growth stages but also different seasons. The results suggest that the regression equation developed in this study can help in optimizing nitrogen fertilization for sweet sorghum production.
\end{abstract}

Keywords: chlorophyll meter, leaf nitrogen concentration, specific leaf area, sweet sorghum [Sorghum bicolor (L.) Moench]

\section{INTRODUCTION}

Sweet sorghum [Sorghum bicolor (L.) Moench] is a promising multipurpose crop and its grain can be used for food, its stalk for ethanol and bagasse and the stripped leaves for fodder. Because of its wide adaptability to

Received 10 March 2011; accepted 13 September 2011.

Address correspondence to H. Uchino. National Agriculture and Food Research Organization, Tohoku Agricultural Research Center, 4 Akahira, Shimo-kuriyagawa, Morioka, Iwate 020-0198, Japan. E-mail: uchino17@gmail.com 
dry conditions as well as its multiple usages, sweet sorghum has a great potential to increase the income of smallholder farmers in the semi-arid tropics (Rao et al., 2009). To make sweet sorghum a profitable crop, there is an obvious need to develop appropriate agricultural practices such as optimum nitrogen $(\mathrm{N})$ fertilization of the crop.

Satisfying the crop demand for $\mathrm{N}$ is important for increasing $\mathrm{N}$ use efficiency and minimizing its loss. Using a chlorophyll meter (SPAD-502; Konica Minolta Sensing, Tokyo, Japan) is one of the nondestructive methods to monitor the $\mathrm{N}$ status of crops. For example, SPAD reading has been used to predict the demand for $\mathrm{N}$ fertilizer topdressings in rice (Oryza sativa L.) (Cabangon et al., 2011), maize (Zea mays L.) (Varinderpal-Singh et al., 2011) and wheat (Triticum aestivum L.) (Fox et al., 1994) crops.

The chlorophyll meter calculates SPAD reading based on the amount of light transmitted by the leaf in two wavelength regions, a red region $(\sim 650 \mathrm{~nm})$ and an infrared region $(\sim 940 \mathrm{~nm})$. It has been reported that there is a strong correlation between SPAD reading and leaf nitrogen concentration (LNC) in various plant species including rice (Peng et al., 1993; Gholizadeh et al., 2009), maize (Dwyer et al., 1991) and woody plants (Van den Berg and Perkins, 2004). However, there is only one report on the relationship between SPAD readings and LNC in sorghum (Yamamoto et al., 2002).

In addition, the correlation equations between SPAD reading and $\mathrm{LNC}$ differed markedly depending on the growth stages (Peng et al., 1993) and growing conditions (Campbell et al., 1990). Difference in the leaf thickness may also contribute to the variability in the relationships between the SPAD reading and LNC (Campbell et al., 1990). Therefore, this issue should be addressed to generalize the usefulness of the chlorophyll meter for estimating LNC under different growth stages and growing conditions in sweet sorghum.

The objective of this study, therefore, was 1) to evaluate the relationship between SPAD reading and LNC, 2) to examine the effect of leaf thickness on this relationship and 3) to determine the applicability of the regression equation developed at various growth stages and growing conditions in sweet sorghum.

\section{MATERIALS AND METHODS}

Field experiments were conducted at the International Crops Research Institute for the Semi-Arid Tropics (ICRISAT) farm in Patancheru, Andhra Pradesh, India $\left(17.53^{\circ} \mathrm{N}, 78.27^{\circ} \mathrm{E}\right)$ in the 2009 and 2010 rainy seasons (June-October). The soil at the experiment was an Alfisol (Ferric Luvisol (FAO classification), Udic Rhodustalf (USDA classification)) with a $\mathrm{pH}$ of 7.9. Promising sweet sorghum hybrid in India 'CSH22SS' (Rao et al., 2009) 
was used in the study. The crops were sown on 16 June 2009 and 21 June 2010 during the two seasons. To create a large variation in leaf $\mathrm{N}$ status, six $\mathrm{N}$ fertilizer rates $\left(0,30,60,90,120\right.$ and $\left.150 \mathrm{~kg} \mathrm{~N}^{-1}\right)$ were arranged in a randomized complete block design with three replications.

Twenty of second topmost fully expanded leaves were collected from each of the 18 plots ( 6 treatments $\times 3$ replications) at two different growth stages: one week before panicle initiation stage (38 days after sowing) and booting stage ( 78 days after sowing) of growth in both the years. After cleaning dust from the leaf surface, an average of SPAD readings at 10-20 points (according to leaf size) using a chlorophyll meter (SPAD-502) was recorded for each leaf. Following this, the twenty leaves sampled from each plot were divided into four groups according to the SPAD readings. The first group consisted of the leaves from 1st to 5th smallest SPAD readings, 2nd group was from 6 th to 10 th, third group was from 11 th to 15 th and fourth group was from 16th to 20th. Leaf area of each of the leaf groups was measured by an automatic area meter (LI-3100, LI-COR, Lincoln, NE, USA). Leaf dry weight was measured after drying the leaves for more than 72 hours at $60^{\circ} \mathrm{C}$, and LNC in leaf digests was determined using an autoanalyser (Sahrawat et al., 2002). Meteorological data on mean air temperature and precipitation were obtained from the ICRISAT weather station in Patancheru, India.

Regression analyses among plant leaf traits were conducted using the SPSS software (version 14.0J, SPSS Inc., Chicago, IL, USA). Difference between simple regression equations was tested with co-variance analysis.

\section{RESULTS AND DISCUSSION}

The air temperature was the highest in June $\left(\mathrm{ca} .30^{\circ} \mathrm{C}\right)$ in both the years and was slightly higher in the 2009 season than in 2010 during the study period (Table 1). Precipitation was markedly low (59 mm) in July 2009 due to a long dry spell. Though furrow irrigation was conducted during this dry spell, still the plants exhibited water stress symptoms such as leaf-rolling. Precipitation in August was markedly higher (>37-year average) in both the years.

TABLE 1 Monthly temperature $\left({ }^{\circ} \mathrm{C}\right)$ and precipitation $(\mathrm{mm})$ on experimental period (2009 and 2010) and on long-term average (1974-2010)

\begin{tabular}{|c|c|c|c|c|c|c|}
\hline \multirow[b]{2}{*}{ Month } & \multicolumn{3}{|c|}{ Temperature } & \multicolumn{3}{|c|}{ Precipitation } \\
\hline & 2009 & 2010 & 1974-2010 & 2009 & 2010 & 1974-2010 \\
\hline June & 30.4 & 29.7 & 29.0 & 97.6 & 139.8 & 111.9 \\
\hline July & 27.6 & 25.9 & 26.6 & 59.2 & 274.8 & 188.3 \\
\hline August & 27.0 & 26.0 & 25.6 & 420.2 & 434.9 & 236.4 \\
\hline September & 26.6 & 26.0 & 25.8 & 264.6 & 132.2 & 155.0 \\
\hline
\end{tabular}


TABLE 2 SPAD reading, specific leaf area (SLA, $\mathrm{cm}^{2} \mathrm{~g}^{-1}$ ) and leaf nitrogen concentration (LNC, \%) of sweet sorghum leaves at two growth stages in 2009 and 2010 rainy seasons

\begin{tabular}{|c|c|c|c|c|c|c|}
\hline \multirow[b]{2}{*}{ Growth stage } & \multicolumn{2}{|c|}{ SPAD } & \multicolumn{2}{|c|}{ SLA } & \multicolumn{2}{|c|}{ LNC } \\
\hline & 2009 & 2010 & 2009 & 2010 & 2009 & 2010 \\
\hline \multicolumn{7}{|c|}{ One week before panicle initiation } \\
\hline Min. & 31.3 & 27.0 & 206 & 224 & 2.04 & 2.01 \\
\hline Max. & 44.0 & 46.9 & 307 & 326 & 3.45 & 3.61 \\
\hline Mean & 38.2 & 39.8 & 242 & 275 & 2.81 & 2.77 \\
\hline \multicolumn{7}{|c|}{ Booting } \\
\hline Min. & 25.9 & 20.2 & 157 & 138 & 1.33 & 1.01 \\
\hline Max. & 48.0 & 53.0 & 241 & 246 & 2.73 & 2.62 \\
\hline Mean & 38.7 & 37.2 & 196 & 194 & 2.19 & 1.90 \\
\hline t-test ${ }^{\mathrm{a}}$ & NS & $*$ & $* * *$ & $* * *$ & $* * *$ & $* * *$ \\
\hline
\end{tabular}

${ }^{\mathrm{a}} \mathrm{t}$-test for the difference between mean values at two growth stages in each year.

*, significant at $5 \%$ probability level. ***, significant at $0.1 \%$ probability level. NS, not significant.

SPAD readings ranged from 20.2 to 53.0 (Table 2), which was within the reported range for sorghum (Yamamoto et al., 2002). The SPAD reading values differed significantly between the two growth stages in 2010: it was higher at one week before panicle initiation stage than at the booting stage. Specific leaf area (SLA = leaf area / leaf dry weight) ranged from 138 to $326 \mathrm{~cm}^{2} \mathrm{~g}^{-1}$ and was significantly lower (i.e. leaf was thicker) at the booting stage than at one week before panicle initiation stage in both the years. Dolciotti et al. (1998) also reported lower SLA at the later growth stages of sorghum crop. In addition, the SLA at one week before panicle initiation stage was lower in the 2009 season than in the 2010 season, probably due to the drought stress at the early growth stage in the 2009 season (Table 1 ). Liu and Stützel (2004) reported a significant increase of leaf thickness due to drought stress. The LNC ranged from 1.01 to $3.61 \%$ and was significantly higher at one week before panicle initiation stage than at the booting stage in both the years (Table 2).

There were significant and positive correlations between SPAD reading and LNC at each growth stage in both the years (Figure 1). The coefficients of determination $\left(\mathrm{R}^{2}\right)$ indicated that $42-88 \%$ of the variation in LNC was explained by SPAD reading at the each growth stage. These results show that the SPAD readings can be used as an effective indicator for evaluating the difference in LNC when comparing at the same growth stages in different seasons.

However, simple regression equations differed significantly between the two growth stages in both $2009(P<0.001)$ and $2010(P<0.001)$ seasons, and the coefficient of determination decreased considerably when the data of the two growth stages were pooled (Figure 1). When comparing the SPAD value at the same LNC, it was higher at the booting stage than at one week before panicle initiation stage in both the years. Peng et al. (1993) reported 

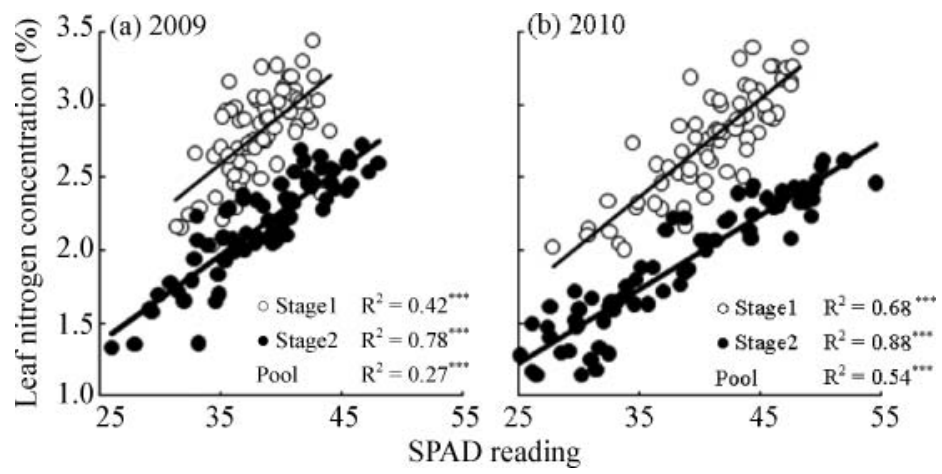

FIGURE 1 Relationships between SPAD readings and leaf nitrogen concentration at 1 week before panicle initiation stage (stage 1) and at the booting stage (stage 2) of sweet sorghum crop in 2009 and 2010 seasons. $^{* * *}$, significant at $0.1 \%$ level of probability.

higher SPAD readings with similar LNC at later growth stage in rice, and most of the variation in the relationships between SPAD reading and LNC could be explained by the difference in leaf thickness. Yamamoto et al. (2002) also reported the importance of considering leaf thickness to understand more precisely the relationship between SPAD reading and leaf chlorophyll content.

To estimate the LNC more precisely over various growth stages, a multiple regression using stepwise method was performed with LNC as the dependent variable and SPAD reading and SLA as the independent variables. Both independent variables were significant in explaining the variability in LNC and the regression equation in 2009 was as follows:

$$
\begin{aligned}
\mathrm{LNC} & =-2.65+0.0765 \times \mathrm{SPAD}+0.0101 \times \mathrm{SLA}\left(\mathrm{R}^{2}=0.71, \mathrm{P}<0.001\right. \\
\mathrm{n} & =144)
\end{aligned}
$$

The coefficient of determination of this equation is significant and very high: this regression equation can explain $71 \%$ of the total variation in LNC.

To assess the accuracy of this equation over years, regression equation 1 was applied to the dataset obtained in 2010 , i.e., we substituted the SPAD readings and SLA in 2010 into regression equation 1 and compared predicted LNC with observed LNC. The predicted LNC correlated strongly with the observed LNC $\left(\mathrm{R}^{2}=0.89, P<0.001\right)$ and the scatter of data concentrated in the vicinity of the 1:1 line (Figure 2 ). These results indicate that the regression equation 1 can be used to estimate LNC accurately using SPAD reading and SLA, and is probably applicable at different growth stages and seasons.

It cannot be disregarded, however, that our results were based only on one sweet sorghum genotype. Peng et al. (1993) compared the relationships between SPAD readings and LNC of five rice genotypes, and revealed that 


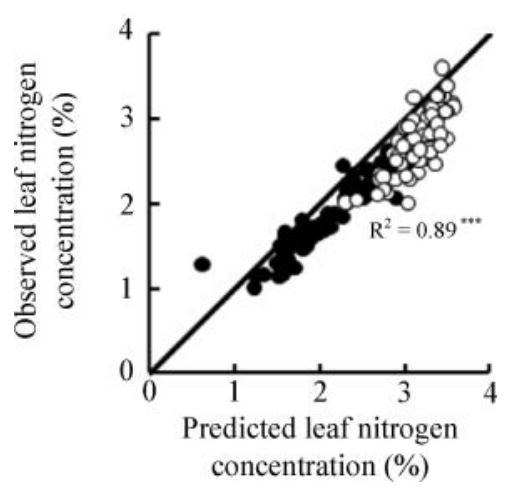

FIGURE 2 Relationships between predicted leaf nitrogen concentration calculated by multiple regression equation 1 and observed leaf nitrogen concentration in 2010.॰, 1 week before panicle initiation stage; $\bullet$, booting stage. ${ }^{* * *}$, significant at $0.1 \%$ level of probability. Solid line indicates 1:1 line.

the relationships varied between genotypes and this variation was improved by taking SLA into regression equation. On the other hand, Yamamoto et al. (2002) reported that the relationships between SPAD reading and the leaf chlorophyll concentration did not differ significantly between the two sorghum genotypes. Further discussion is difficult here because there are few reports on the varietal difference of SPAD-LNC relationships in sorghum. Further studies are needed to confirm the stability of the regression equation 1 developed in this study not only to growth stages and growing conditions, but also to genotypes.

\section{CONCLUSIONS}

There were significant correlations between SPAD reading and LNC at each growth stage of sweet sorghum, indicating that LNC can be estimated from SPAD reading when comparing at the same growth stage. However, the correlations between SPAD reading and LNC were very poor when the data of the two growth stages were pooled. This poor correlation was improved when SLA was introduced as a second independent variable in the multiple regression analysis (equation 1). The regression equation obtained in this study was applicable to not only different growth stages but also different years with different growing conditions. It is indicated that this equation will help to optimize $\mathrm{N}$ fertilization of sweet sorghum production in the semi-arid tropical regions.

\section{ACKNOWLEDGMENTS}

We thank Mr. K. Papa Rao, Mr. P. V. Satish and Mr. M. Vishwanath, of ICRISAT and Mr. T. Naya of Crop Science Laboratory, Hokkaido University, 
for their dedicated support. This study was a part of a research project "Development of sustainable soil fertility management for sorghum and sweet sorghum through effective use of biological nitrification inhibition (BNI)" and was funded by grants from the Ministry of Agriculture, Forestry and Fisheries, Japan.

\section{REFERENCES}

Cabangon, R. J., E. G. Castillo, and T. P. Tuong. 2011. Chlorophyll meter-based nitrogen management of rice grown under alternate wetting and drying irrigation. Field Crops Research 121: 136-146.

Campbell, R. J., K. N. Mobley, R. P. Marini, and D. G. Pfeiffer. 1990. Growing conditions alter the relationship between SPAD-501 values and apple leaf chlorophyll. HortScience 25: 330-331.

Dolciotti, I., S. Mambelli, S. Grandi, and G. Venturi. 1998. Comparison of two sorghum genotypes for sugar and fiber production. Industrial Crops and Products 7: 265-272.

Dwyer, L. M., M. Tollenaar, and L. Houwing. 1991. A nondestructive method to monitor leaf greenness in corn. Canadian Journal of Plant Science 71: 505-509.

Fox, R. H., W. P. Piekielek, and K. M. Macneal. 1994. Using a chlorophyll meter to predict nitrogen fertilizer needs of winter wheat. Communications in Soil Science and Plant Analysis 25: 171-181.

Gholizadeh, A., M. S. M. Amin, A. R. Anuar, and W. Aimrun. 2009. Evaluation of leaf total nitrogen content for nitrogen management in a Malaysian paddy field by using soil plant analysis development chlorophyll meter. American Journal of Agricultural and Biological Sciences 4: 278-282.

Liu, F., and H. Stützel. 2004. Biomass partitioning, specific leaf area, and water use efficiency of vegetable amaranth (Amaranthus spp.) in response to drought stress. Scientia Horticulturae 102: 15-27.

Peng, S., F. V. Garcia, R. C. Laza, and K. G. Cassman. 1993. Adjustment for specific leaf weight improves chlorophyll meter's estimate of rice leaf nitrogen concentration. Agronomy Journal 85: 987-990.

Rao, P. S., S. S. Rao, N. Seetharama, A. V. Umakanth, P. S. Reddy, B. V. S. Reddy, and C. L. L. Gowda. 2009. Sweet sorghum for biofuel and strategies for its improvement. Information Bulletin no. 77. Patancheru, India: International Crops Research Institute for the Semi-Arid Tropics.

Sahrawat, K. L., G. Ravi Kumar, and K. V. S. Murthy. 2002. Sulfuric acid-selenium digestion for multielement analysis in a single plant digest. Communications in Soil Science and Plant Analysis 33: 3757-3765.

Van den Berg, A. K., and T. D. Perkins. 2004. Evaluation of a portable chlorophyll meter to estimate chlorophyll and nitrogen contents in sugar maple (Acer saccharum Marsh.) leaves. Forest Ecology and Management 200: 113-117.

Varinderpal-Singh, Yadvinder-Singha, Bijay-Singh, H. S. Thind, A. Kumar, and M. Vashistha. 2011. Calibrating the leaf color chart for need based fertilizer nitrogen management in different maize ( $\mathrm{Zea}$ mays L.) genotypes. Field Crops Research 120: 276-282.

Yamamoto, A., T. Nakamura, J. J. Adu-Gyamfi, and M. Saigusa. 2002. Relationship between chlorophyll content in leaves of sorghum and pigeonpea determined by extraction method and by chlorophyll meter (SPAD-502). Journal of Plant Nutrition 25: 2295-2301. 